\title{
To Determine the Anteroposterior Position of Incisors in Relation to Points A and B on Cephalogram and Study Models in North Indian Population
}

\author{
Mandeep K. Bhullar ${ }^{1}$ Priyanka Chaudhary ${ }^{1} \quad$ Sanjay Mittal ${ }^{1} \quad$ Isha Aggarwal ${ }^{1} \quad$ Merry Goyal $^{1}$ \\ Tanzin Palkit ${ }^{1}$
}

1Department of Orthodontics and Dentofacial Orthopaedics, Bhojia Dental College and Hospital, Baddi, Himachal Pradesh, India

Address for correspondence Priyanka Chaudhary, MDS, Department of Orthodontics and Dentofacial Orthopaedics, Bhojia Dental College and Hospital, Baddi, Himachal Pradesh 173205, India (e-mail: chdrypriyanka.64@gmail.com).

Dent J Adv Stud 2020;8:40-43

\begin{abstract}
Introduction This study aimed to determine the upper and lower incisors to points $A$ and $B$ on lateral cephalogram and study model in North Indian population. This article evaluated the present relationship of upper and lower incisors position to point $A$ and $B$ on the cephalogram and studied the model as a diagnostic tool for orthodontic treatment planning.

Materials and Methods The study included 32 patients, aged 15 to 25 years. The sample was divided into two groups as group I ( $n=32$, cephalometric analysis) and group II ( $n=32$, study model analysis) of the same patient. In group I incisors position was related to points $A$ and $B$ on the cephalograms and in group II incisors position was related to points $A$ and $B$ on study model by using transparent grid.

Results As per Indian norms, outcome mean value for cephalometric norms was 6.3 and $3.2 \mathrm{~mm}$ and for study model norms was 4 and $1.3 \mathrm{~mm}$. Statistically significant differences $(p<0.002)$ were observed for mandibular incisor position on cephalograms and for maxillary incisors $(p<0.001)$ on study casts when compared

Keywords

- cephalometrics

- incisor position

- study model with Chile sample norm.

Conclusion The anteroposterior position of upper and lower incisors in relation to points A and B on cephalogram and casts has been determined in North Indian patients.
\end{abstract}

\section{Introduction}

Points A and B are commonly used as skeletal landmarks in cephalometric studies that investigate the efficacy of various treatment modalities on the sagittal relationship between the maxilla and mandible. ${ }^{1}$ The ability to determine the anteroposterior (AP) position of a patient's incisors from model analysis could be highly useful in forming an initial diagnosis before the cephalometric tracing is available. Such a technique would also be helpful during treatment, when brackets can mask the true positions of the teeth and lips. ${ }^{2}$

Point $\mathrm{A}$ is the most posterior midline point in the concavity between the anterior nasal spine and the prosthion. Point
$\mathrm{B}$ is the most posterior midline point in the concavity of the mandible between the most superior point on the alveolar bone overlying the lower incisor and pogonion ${ }^{1}(-$ Fig. 2A).

$A-B$ plane is formed by joining of points $A$ and $B$. The A-B plane is a measure of the relation of the anterior limit of the apical bases to each other relative to the facial line. It represents an estimate of the difficulty in obtaining the correct axial inclination and incisor relationship when using orthodontic therapy. Because point $B$ is positioned behind point $A$, this angle is usually negative in value, except in class III malocclusions or class I occlusions with prominence of the mandible. A large negative value suggests a class II facial pattern. ${ }^{1}$
DOI https://doi.org/ 10.1055/s-0040-1710197 ISSN 2321-1482.
License terms

()(1) $\Theta \circledast$ 
It can been seen on head films that in cases of excessive prominence or flattening of the chin, the A-B line relates more closely to the incisors than does the AP line, which tends to follow the forward or backward configuration of the chin. Therefore, using A-B rather than AP as a diagnostic guide can prevent excessive advancement or retraction of the incisors during treatment (-Fig. 1).

Head films that in cases of excessive prominence or flattening of the chin, the A-B line relates more closely to the incisors than does the AP line, which tends to follow the forward or backward configuration of the chin. Therefore, using A-B rather than AP as a diagnostic guide can prevent excessive advancement or retraction of the incisors during treatment (-Fig. 1).

The Wits' appraisal of jaw disharmony is a measure of the extent to which the jaws are related to each other anteroposteriorly. Harvold ${ }^{3}$ likewise used an occlusal plane for the prediction of growth patterns of the jaws. He projected points $A$ and $B$ onto the occlusal plane and named the resultant measurement the A-B difference. A negative value is assigned to measurements in which point $B$ is posterior to point $A$.

Valenzuela and Madsen ${ }^{4}$ have previously observed that Downs's points A and B and the functional occlusal plane can be identified on study casts. They determine the positions of the incisors and the skeletal relationship of the jaws, using the A-B line and applying the Wits' appraisal to the study casts through a transparent millimeter grid. Because the measurements of Valenzuela and Madsen are related to the incisal edges of the incisors, the jaws must be separated to visualize the relationship. The following study was devised to calculate normal values.

\section{Materials and Methods}

The study included 32 patients, aged 15 to 25 years. The sample was divided into two groups as group I ( $n=32$, cephalograms) and group II ( $n=32$, study models). The inclusion criteria were patient's age should be between 15 and 25 years for both males and females, lateral cephalogram and study model should be pretreatment and they were of sufficient quality to allow identification of relevant landmarks, class I molar occlusion, a harmonious profile, and normal lip closure.

In group I incisors position was related to points A and B on the cephalograms and in group II incisors position was related to points A and B on study models.

\section{Group 1: Cepahlometric Analysis}

To determine the position of the incisors on lateral cephalogram, the landmark (points A and B) was traced on the tracing sheet and a line was drawn between points $\mathrm{A}$ and $\mathrm{B}$, and the distances were measured from the incisal third of the maxillary and mandibular incisors labial surfaces, respectively (-Fig. $\mathbf{2 A}$ ).
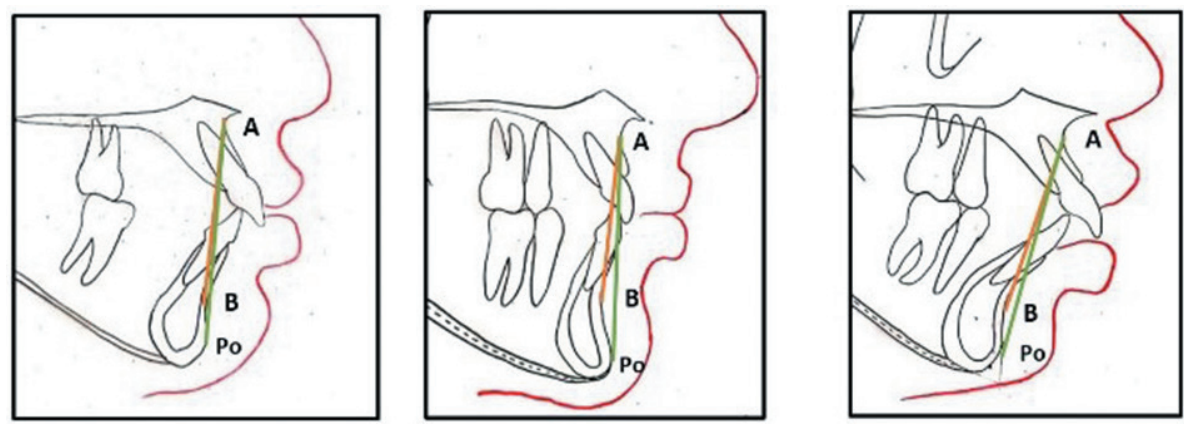

Fig. 1 A-B line is more accurate than AP line in determining incisor position in cases where chin is prominent or recessive. AP, anteroposterior; Po, posterior.
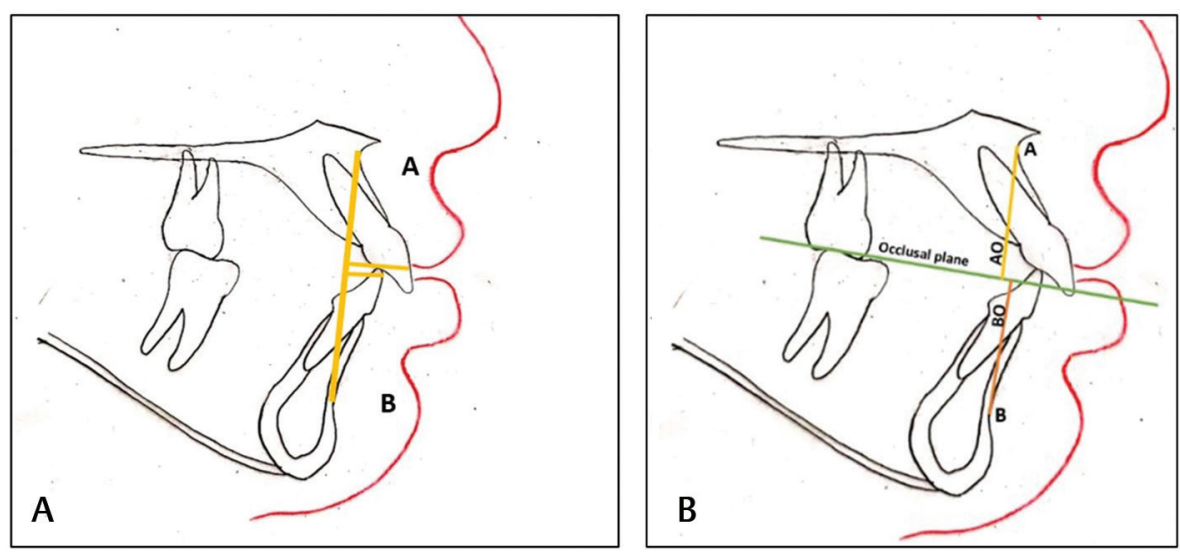

Fig. 2 (A) showing the distances from labial surfaces of maxillary and mandibular incisors to cephalometric (osseous) A-B line (yellow line). (B) Wits' analysis method. O, occlusal. 


\section{Wits' Analysis: Cepahlometric Study}

To determine the position of the incisors on cephalogram, a perpendicular line was dropped from point $A$ to the functional occlusal plane (A-O; occlusal plane was drawn through the region of maximum cuspal interdigitation/region of overlapping of cusps of first premolars and first molars) and extended to the level of point B., ${ }^{5,6}$

The distance from point $B$ to this perpendicular was then used to establish the $\mathrm{AO}-\mathrm{OB}$ intermaxillary relationship (-Fig. 2B).

\section{Group 2: Study Model Analysis}

To determine the position of the incisors relative to the gingival A-B line on study casts first gingival points A and B were drawn with a pencil as two round marks on the study model, it should be $3 \mathrm{~mm}$ in diameter and near the apices of the left or right maxillary and mandibular central incisors at the point of greatest concavity ${ }^{2}$ as shown in ( - Fig. $\left.\mathbf{3 A}\right)$.

\section{Method}

The study casts are held in occlusion with one hand and viewed laterally through a transparent millimeter grid-a transparent photocopy of millimeter-ruled paper was used as shown in the picture. The grid was held with the other hand so that the labial contour of the incisors was lined against a dark background (-Fig. 3B).

The transparency was placed with a main centimeter line over gingival points $A$ and $B$, and the line of occlusion was held vertically so that the A-B line was horizontal to the eye of the observer.
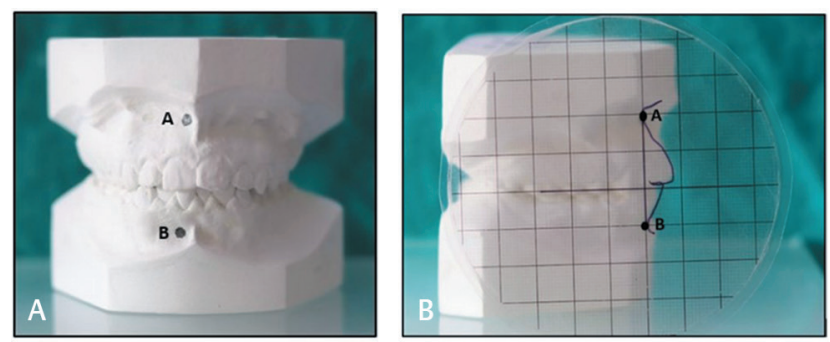

Fig. 3 (A) Apical points A and B marked on study casts. Normal distances from labial surfaces of maxillary and mandibular incisors to gingival A-B line. (B) Incisal contours and marks of points A and B viewed through transparent millimeter grid (a transparent photocopy of millimeter-ruled paper).

\section{Wits' Analysis: Study Model Analysis}

To determine the position of the incisors on the study casts, perpendiculars from gingival points $A$ and $B$ to the occlusal plane were coincident, and that the gingival $A-B$ line was also perpendicular to the functional occlusal plane. The transparent millimeter grid was placed against the occluding casts so that a main horizontal centimeter line coincided with the functional occlusal plane and a main perpendicular line passed through gingival point $A$. If gingival point $B$ falls behind the vertical line, a diagnosis of skeletal class II is made; if point $B$ is ahead of the line, a class III jaw relationship exists ( - Fig. 4).

\section{Result}

Result showed Indian norms mean value for cephalometric norms were 6.3 and $3.2 \mathrm{~mm}$ and for study model norms were 4 and $1.3 \mathrm{~mm}$.

Descriptive statistics for the cephalometric study group (group 1) and study model group (group 2) for the maxillary and mandibular incisor to the A-B line in the Indian population. Independent $t$-test showed the statistically significant difference $(p<0.002)$ for mandibular incisor (group 1) and statistically significant difference $(p<0.001)$ for maxillary incisor (group 2) between the Chilean Norm and Indian Norm in cephalometric study group (group 1) and in study model group (group 2) (-Table 1).

Result for total sample of the study model group for the maxillary and mandibular incisors labial surface to A-B line in the Chilean norm and Indian norm showed descriptive statistics, mean value for the Chilean value is 2.5 , and the Indian value is 2.7 . Independent $t$-test showed a nonsignificant difference for maxillary and mandibular incisor between in the Chilean norm and Indian norm in group 2 (-Table $\mathbf{1}$ ).

\section{Discussion}

Previous cephalometric studies of the sample indicated that the mean distances of the maxillary and mandibular incisors to AP were 5 and $2 \mathrm{~mm}$, respectively, and the mean interincisal angle was 129 degrees. ${ }^{78}$ In mean sample of patients with good occlusions, the mean distances from the labial surfaces of the maxillary and mandibular incisors to the cephalometric (osseous) A-B line were 7 and $4 \mathrm{~mm}$, respectively. ${ }^{9}$
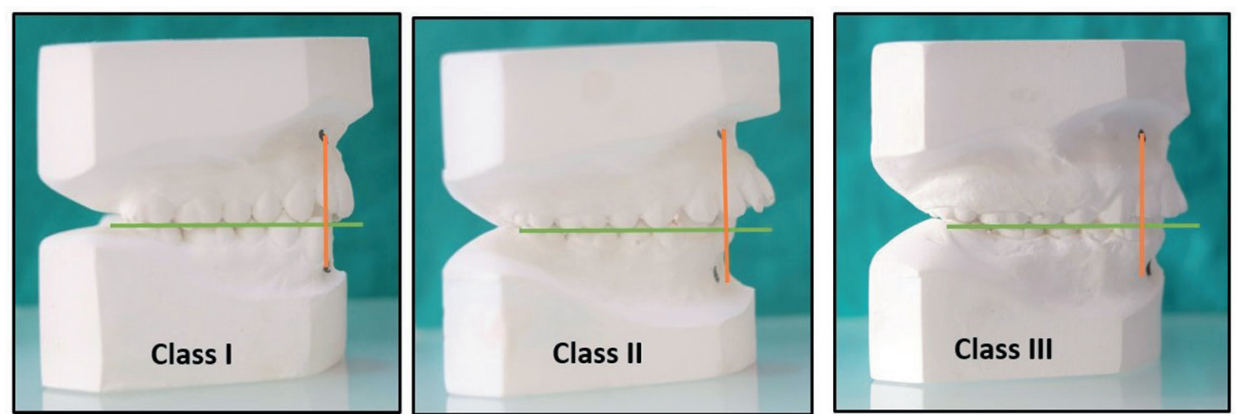

Fig. 4 In Wits' appraisal of study casts, normal distance of gingival point B to perpendicular from gingival point A to functional occlusal plane was measured. 
Table 1 Descriptive statistics showing means and its derivatives and independent $t$-test in groups 1 and 2 and total sample of group 2 for maxillary and mandibular incisors in Indian population

\begin{tabular}{|c|c|c|c|c|c|c|c|c|}
\hline \multirow{3}{*}{ Groups } & \multicolumn{8}{|c|}{ Descriptive statistics } \\
\hline & \multirow[t]{2}{*}{ Parameters } & \multirow[t]{2}{*}{$n$} & \multirow[t]{2}{*}{ Means } & \multirow{2}{*}{$\begin{array}{l}\text { Standard } \\
\text { deviation }\end{array}$} & \multirow{2}{*}{$\begin{array}{l}\text { Standard } \\
\text { error of } \\
\text { mean }\end{array}$} & \multicolumn{2}{|c|}{$95 \% \mathrm{Cl}$} & \multirow[t]{2}{*}{ Sig (2 tailed } \\
\hline & & & & & & Lower & Upper & \\
\hline \multirow[t]{2}{*}{ Group 1} & Maxillary incisors & 32 & 6.500 & 1.218 & 0.215 & 0.069 & 0.930 & 0.024 \\
\hline & $\begin{array}{l}\text { Mandibular } \\
\text { incisors }\end{array}$ & 32 & 3.250 & 1.295 & 0.228 & 0.292 & 1.207 & 0.002 \\
\hline \multirow[t]{2}{*}{ Group 2} & Maxillary incisors & 32 & 1.375 & 0.609 & 0.107 & -0.590 & -0.159 & 0.001 \\
\hline & $\begin{array}{l}\text { Mandibular } \\
\text { incisors }\end{array}$ & 32 & 4.031 & 0.694 & 0.122 & -0.276 & 0.214 & 0.800 \\
\hline $\begin{array}{l}\text { Total sample } \\
\text { (group 2) }\end{array}$ & $\begin{array}{l}\text { Maxillary and } \\
\text { mandibular } \\
\text { incisors }\end{array}$ & 32 & 2.703 & 1.487 & 0.185 & -0.727 & 0.321 & 0.445 \\
\hline
\end{tabular}

Abbreviation: $\mathrm{Cl}$, confidence interval.

Note: Independent $t$-test showed statistically significant difference $(p<0.002)$ for Mandibular incisor (group 1$)$ and statistically significant difference $(p<0.001)$ for maxillary incisor (group 2$)$ between in the Chilean norm and Indian norm in cephalometric study group.

The normal distances from gingival points $A$ and $B$ to the labial surfaces of the maxillary and mandibular central incisors on the casts were found to be 4 and $1 \mathrm{~mm}$, respectively. ${ }^{2}$

If the distance between the perpendicular line and the incisal third of the labial surface of the maxillary incisor is more than $4 \mathrm{~mm}$, the incisor is protrusive; if it is less than $4 \mathrm{~mm}$, the incisor is retrusive. Mandibular incisor protrusion is measured similarly, using gingival point B and the norm of $1 \mathrm{~mm}^{2}$

In Wits' analysis, the mean distance between point $\mathrm{B}$ and the perpendicular from point $A$ to the functional occlusal plane was $1 \mathrm{~mm}$ in the cephalometric method. Wits' analysis on the study cast resulted in a distance of $0 \mathrm{~mm}$ from gingival point $B$ to the perpendicular from gingival point $A$ to the functional occlusal plane. Consequently, the position of the incisors can be analyzed independent of the anteroposterior jaw relationship, using the same norms of 4 and $1 \mathrm{~mm} .^{2}$

The present study provides Indian norms; mean value for cephalometric norms was 6.3 and $3.2 \mathrm{~mm}$ and mean value for study model norms was 4 and $1.3 \mathrm{~mm}$ as compared with the Chilean norms, ${ }^{2}$ that is, 7 and $4 \mathrm{~mm}$ for cephalometric study and 4 and $1 \mathrm{~mm}$ for study model.

Using the cephalometric A-B line will prevent undesirable advancement or retraction of the incisors.

Results showed that mandibular incisor are less protrusive to $A-B$ plane in the cephalometric study and maxillary incisors are more protrusive to A-B plane on the study model in the Indian norm as compared with Chilean norms.

\section{Conflict of Interest}

None declared.

\section{References}

1 Jacobsen A, Jacobsen R, Radiographic Cephalometry: From Basics to 3D Imaging. Carol Stream, IL: Quintessence Publishing Co; 1995

2 Madsen R, Escobar PP, Torres L, Sandoval P. Relating the incisors to points A and B in cephalometric, model, and clinical analysis. J Clin Orthod 2001;35(5):315-320

3 Harvold E. Some biologic aspects of orthodontic treatment in the transitional dentition. Am J Orthod 1963;49:1-14

4 Valenzuela J, Madsen R. Position of the incisors and Wits relation of the apical bases in study models. Rev. Chil. Orthod 1986;3:90-100

5 Jacobson A. Update on the Wits appraisal. Angle Orthod 1988;58(3):205-219

6 Jenkins DH. Analysis of orthodontic employing lateral cephalometric radiography. Am J Orthod 1952;41:442-452

7 Morales R, et al. Cephalometric evaluation of a sample of Chilean subjects in lateral radiographs. Rev. Chil. Ortod 1988;5:11-20

8 Ravera MJ, Carvajal R, Madsen R. A study of the interincisal angle in the Chilean population and its comparison with international cephalometric values. Rev. Chil. Ortod 1991;8:25-34

9 Madsen R, Paniagua H. Maxillo-mandibular sagittal relations in the lateral facial examination. Odontol Chil 1989; 37(1):161-167 